\title{
Doenças e características físicas e químicas pós-colheita em manga
}

\section{Postharvest diseases and physicochemical characteristics of mango}

\author{
Ivan Herman Fischer ${ }^{1 *}$; Maria Cecília de Arruda ${ }^{2}$; \\ Aparecida Marques de Almeida ${ }^{3}$; Sonia Maria Nalesso Marangoni Montes"; \\ Elisangela Marques Jerônimo ${ }^{5}$; Eliane Maria Ravasi Stefano Simionato ${ }^{6}$; \\ Rosemary Marques de Almeida Bertani ${ }^{7}$
}

\section{Resumo}

O presente trabalho objetivou identificar e quantificar as doenças pós-colheita e avaliar as características físicas e químicas de frutos de manga cultivares Haden, Tommy Atkins, Palmer e Keitt submetidos, ou não, ao tratamento com o fungicida carbendazim. Os frutos foram colhidos em um pomar comercial em Presidente Prudente-SP, individualizados e submetidos a $24 \mathrm{~h}$ de câmara úmida, permanecendo por mais oito dias a $25 \pm 2^{\circ} \mathrm{C}$ e $70-80 \%$ de UR. A incidência de doenças, a firmeza e a perda de massa foram avaliadas periodicamente, durante nove dias. Antes e ao final do armazenamento, os frutos foram caracterizados quanto aos teores de acidez titulável e sólidos solúveis. A ocorrência de podridões foi elevada nas quatro cultivares de manga. A antracnose foi a doença mais freqüente, com praticamente $100 \%$ de incidência nos frutos. A podridão peduncular de Lasiodiplodia teve maior incidência na cv. Tommy Atkins (68\%), seguida pela Haden (36\%). O tratamento com carbendazim apresentou eficiência variável no controle das podridões, em função da cultivar de manga, podendo ser recomendado para o controle da podridão peduncular nas cvs. Haden e Palmer e também para reduzir a severidade da antracnose nas cvs. Haden e Keitt. A aplicação de fungicida não influenciou nos teores de sólidos, acidez titulável e "ratio" das cultivares de manga, exceto na Palmer que apresentou menor "ratio" quando tratada com fungicida. A aplicação de ethefon não interferiu no processo de amadurecimento da manga cv. Haden.

Palavras-chave: Mangifera indica, Colletotrichum, Lasiodiplodia, qualidade

\begin{abstract}
The objective of this work was to identify and to quantify the postharvest diseases and to evaluate the physical and chemical characteristics of mango fruits cvs. Haden, Tommy Atkins, Palmer and Keitt, submitted or not to the treatment with the fungicide carbendazim. The fruits had been harvested in a commercial orchard in President Prudente-SP, individualized and kept in a humid chamber for $24 \mathrm{~h}$, remaining eight days at $25 \pm 2^{\circ} \mathrm{C}$ and $70-80 \%$ RH. The incidence of diseases, the firmness and the loss of mass were evaluated periodically, during nine days. Before and to the end of the storage, the fruits had been characterized to titratable acidity and soluble solids content. There was high occurrence of
\end{abstract}

1 Engenheiro Agrônomo, Doutor em Fitossanidade, Agência Paulista de Tecnologia dos Agronegócios/APTA Regional Centro Oeste. Bauru, SP. E-mail: ihfische@aptaregional.sp.gov.br

2 Engenheira Agrônoma, Doutora em Fitotecnia, APTA Regional Centro Oeste - Bauru, SP

3 Engenheira Agrônoma, Doutora em Fitotecnia, APTA Regional Centro Oeste - Bauru, SP

4 Engenheira Agrônoma, Mestre em Fitotecnia, APTA Regional Alta Sorocabana - Presidente Prudente, SP

5 Engenheira Agrônoma, Doutora em Tecnologia de Alimentos, APTA Regional Centro Oeste - Jaú, SP

6 Professora Doutora na Universidade do Sagrado Coração, Bauru, SP

7 Engenheira Agrônoma, Doutora em Fitotecnia, APTA Regional Centro Oeste - Marília, SP

* Autor para correspondência 
rots in the four mango cultivars. Anthracnose was the most frequent disease, with practically $100 \%$ of incidence in the fruits. The Lasiodiplodia stem-end rot had greater incidence in cv. Tommy Atkins (68\%), followed for the Haden (36\%). The treatment with carbendazim presented changeable efficiency in the control of the rots, in function of mango cultivar. This treatment is recommended for the control of the stem-end in cvs. Haden and Palmer and also to reduce the severity of anthracnose in cvs. Haden and Keitt. The fungicide application did not influence soluble solids and titratable acidity content and ratio of mango cultivars, except in Palmer that presented minor ratio when treated with fungicide. The ethefon application did not influence the ripening process of mango cv. Haden.

Key words: Mangifera indica, Colletotrichum, Lasiodiplodia, quality

\section{Introdução}

A vida pós-colheita da manga (Mangifera indica L.) pode ser limitada pelo desenvolvimento de patógenos, principalmente fungos, causadores de podridões, e pela deterioração fisiológica devido ao amadurecimento do fruto, podendo as perdas na pós-colheita alcançar até 30\% dos frutos (SILVA; FONSECA; MOREIRA, 2007). Além disso, a perda de água pelos frutos pode levar ao enrugamento e murchamento dos frutos, comprometendo o aspecto visual e reduzindo o valor comercial destes (PFAFFENBACH et al., 2003).

O reduzido tempo de vida útil na pós-colheita, sob condições normais de temperatura ambiente (oito a doze dias), associado ao curto período de colheita, condicionam a oferta e os preços no mercado. Para uma boa aceitação pelos consumidores, os frutos devem estar túrgidos, sem presença de insetos praga, patógenos e defeitos que alterem a qualidade da polpa (ALVES FILHO, 2002; JERONIMO et al., 2007a).

Dentre as doenças identificadas em pós-colheita da manga, as mais importantes são: a antracnose, causada por Colletotrichum gloeosporioides Pens, e a podridão peduncular, causada por um complexo de fungos, sendo Lasiodiplodia theobromae (Pat.) Griffon \& Maubl. o mais comum, em regiões com clima úmido e quente (FREITAS-SILVA et al., 2002; JUNQUEIRA et al., 2002). A antracnose afeta todas as partes da planta, com prejuízo maior nos frutos, causando manchas escuras irregulares na casca, as quais podem coalescer e atingir grandes áreas do fruto. A podridão peduncular caracteriza-se por uma podridão marrom-escura, com bordas bem definidas, iniciando-se pela região peduncular, local de penetração do patógeno (CUNHA et al., 1993). $\mathrm{Na}$ maioria das vezes, os frutos são infectados no campo por estes patógenos, permanecendo latentes até o estabelecimento de condições favoráveis ao seu desenvolvimento, geralmente na maturação. Assim se faz necessário a adoção de um manejo preventivo adequado, durante a florada e desenvolvimento dos frutos, bem como um manejo na pós-colheita (DODD; PRUSKY; JEFFRIES, 1997). Os prejuízos estão relacionados com a cultivar, pois o grau de tolerância em relação à doença é variável. Pouquíssimas variedades apresentam resistência à antracnose (MARANCA, 1980). Outros patógenos, considerados secundários, podem causar podridões na pós-colheita como, Alternaria alternata (Fr.:Fr) Keissl, Hendersonula toruloidea Nattrass, Diaporthe citri Wolf, Aspergillus flavus Link, Pestalotia mangiferae Henn., Penicillium cyclopium Westling, Dothiorella spp. Phomopsis mangifera Ahmad. (RIBEIRO, 1997) e Rhizopus spp. e as bactérias Erwinia spp. e Xanthomonas campestris pv. mangiferaeindicae Patel, Moniz \& Kulkarni (DODD et al., 1997).

A caracterização de danos pós-colheita busca facilitar a tomada de decisão por parte do produtor, do atacadista e do varejista quanto à necessidade de investimento em medidas de prevenção, pois somente é possível avaliar se a adoção de uma medida de controle é lucrativa ou não, após quantificar os danos causados por determinado patógeno (BARITELLE; GARDNER, 1984). Diante disso, objetivou-se avaliar a incidência e a severidade das doenças de 
pós-colheita, bem como as características físicas e químicas de frutos de manga das cultivares Haden, Tommy Atkins, Palmer e Keitt, tratadas ou não com o fungicida carbendazim na pós-colheita.

\section{Material e Métodos}

Foram utilizados frutos de manga das cvs. Haden, Tommy Atkins, Palmer e Keitt, provenientes de pomar com cultivo convencional, localizado em Presidente Prudente, SP (coordenadas 22\%07'32" S e $51^{\circ} 23^{\prime} 20^{\prime \prime} \mathrm{W}$, com $475 \mathrm{~m}$ de altitude). A cidade apresenta clima subtropical com verões quentes e chuvosos e invernos secos e frios, com uma temperatura e precipitação média mensal, em 2006, de $23,6^{\circ} \mathrm{C}$ e $104,6 \mathrm{~mm}$, respectivamente. O pomar estudado apresentava cerca de 600 plantas de cada cultivar, todas com idade superior a 13 anos, em espaçamento variável entre $9 \times 4 \mathrm{~m}$ para a cv. Palmer, 9 x $6 \mathrm{~m}$ para as cvs. Haden e Keitt e $10 \mathrm{x}$ $8 \mathrm{~m}$ para a cv. Tommy Atkins, com produtividade média anual estimada das cultivares Haden, Tommy Atkins, Palmer e Keitt de 46,6; 19,4; 12,5 e 20,0 t.ha $^{-1}$, respectivamente. O controle fitossanitário, em 2006, caracterizou-se por duas pulverizações foliares com enxofre $\left(2,4\right.$ g. $\left.\mathrm{L}^{-1}\right)$, em maio e junho e, de hidróxido de cobre $\left(1,7\right.$ g.L $\left.\mathrm{L}^{-1}\right)$, de julho a novembro, em intervalos de três semanas. As demais práticas de manejo da cultura seguiram o padrão comercial recomendado para a região.

Os frutos foram colhidos aleatoriamente, de plantas homogêneas no pomar. $\mathrm{Na}$ definição do ponto de colheita, utilizou-se como referência a forma e aspecto do fruto. As cvs. de manga Haden, Tommy Atkins, Palmer e Keitt foram colhidas mensalmente, de novembro de 2006 a fevereiro de 2007, respectivamente, coincidindo com os picos de colheita de cada cultivar na região.

Após a colheita, os frutos foram ou não imersos em suspensão de carbendazim (0,5 g.L $\left.\mathrm{L}^{-1}\right)$. Para a cv. Haden, em adição ao tratamento com carbendazim, os frutos foram ou não pulverizados com ethefon $\left(1,8\right.$ g. $\left.\mathrm{L}^{-1}\right)$, três dias antes da colheita, para acelerar a maturação na pós-colheita. Em seguida, os frutos foram acondicionados em caixas plásticas forradas com saco "tipo bolha", com dimensões externas de $55 \mathrm{~cm}$ de comprimento, $30 \mathrm{~cm}$ de altura e $35 \mathrm{~cm}$ de largura, e transportados ao laboratório da APTA Regional - Bauru/SP, onde foram individualizados em bandejas plásticas e submetidos à câmara úmida por 24 horas, constituída por saco plástico previamente umedecido, visando favorecer a ocorrência das podridões, permanecendo por mais 8 dias em laboratório a $25 \pm 2^{\circ} \mathrm{C}$ e $70-80 \%$ de UR.

$\mathrm{O}$ delineamento experimental foi o inteiramente ao acaso tendo sido avaliados 50 frutos por tratamento e cultivar para avaliação de incidência e severidade de doenças e, doze frutos por tratamento para avaliação física e química dos frutos.

A incidência (número de frutos doentes) e a severidade (área do fruto sintomática) das doenças foram avaliadas visualmente por um único avaliador aos 1, 4, 7 e 9 dias da colheita dos frutos. Quando havia dúvida sobre a doença foram preparadas lâminas com estruturas do patógeno, para sua identificação sob microscópio óptico, e realizado o isolamento em meio de cultura batata-dextroseágar (BDA). Para comprovação da patogenicidade procedeu-se a inoculação dos isolados em frutos sadios, através da substituição de discos da casca por discos de micélio (5,0 $\mathrm{mm}$ de diâmetro). Os discos de micélio foram provenientes de colônias monospóricas cultivadas em meio BDA, durante sete dias (MORAES; ZAMBOLIM; LIMA, 2006).

As características físicas e químicas avaliadas foram: a) pressão de turgescência, determinada pelo método da aplanação (CALBO; NERY, 1995); b) perda de massa fresca, determinada por diferença entre a massa inicial e a massa em cada dia de avaliação; c) teor de sólidos solúveis (SS), determinado em refratômetro digital utilizandose suco homogeneizado da parcela; d) teor de acidez titulável (AT), determinado por titulação com $\mathrm{NaOH}$, utilizando-se suco homogeneizado da parcela; e) "ratio", calculado pela relação entre o 
teor de sólidos solúveis e acidez. A perda de massa fresca e a pressão de turgescência foram avaliadas aos 0, 4, 7 e 9 dias de armazenamento. Os teores de sólidos solúveis e acidez titulável foram avaliados no início e ao final do período de armazenamento, sendo que ao final, os frutos com elevada incidência de podridões (não comercializáveis) não foram incluídos na análise química.

Os dados obtidos de incidência e de severidade das doenças pós-colheita, para os frutos das cultivares de manga e no decorrer do período de armazenamento, foram comparados por meio de teste não paramétrico de comparação de múltiplas proporções, ao nível de $5 \%$ de probabilidade, conforme Zar (1999). Os resultados da avaliação física e química foram submetidos à análise de variância, aplicando-se o teste de Tukey (5\%) para a comparação das médias.

\section{Resultados e Discussão}

Incidência e severidade de doenças pós-colheita

As doenças encontradas em mangas das cvs. Haden, Tommy Atkins, Palmer e Keitt foram antracnose e podridão peduncular de Lasiodiplodia. No início do armazenamento, a incidência da antracnose foi igual ou superior a 50\% nos frutos avaliados (Figura 1). Segundo Choudhury (1991), em levantamento de doenças em pós-colheita em manga 'Tommy Atkins' realizado nas áreas irrigadas do submédio São Francisco do nordeste brasileiro, foram constatados cinco fungos patogênicos, sendo C. gloeosporioides o mais importante, com uma freqüência de 91,7\% nas amostras analisadas. Também na Costa Rica, a antracnose e a podridão peduncular foram consideradas as mais freqüentes na pós-colheita de manga, com 85,7 e 10,4\% de incidência, respectivamente (ARAUZ; UMANA, 1986).

Dentre as cultivares avaliadas a cv. Tommy Atkins foi a que apresentou a menor incidência de antracnose (50,0\%), e a cv. Keitt a maior (96,0\%), no início do armazenamento. Nas cvs. Haden e Palmer foram observados percentuais de 84,0 e 58,0\% para frutos doentes. No nono dia de armazenamento, praticamente todos os frutos apresentavam pelo menos uma mancha de antracnose. O tratamento dos frutos com o fungicida carbendazim não reduziu o aparecimento dos sintomas da antracnose nos frutos (Figura 1).

A incidência da podridão peduncular foi zero no início do armazenamento dos frutos não tratados, mas desenvolveu-se de modo significativo ao final do armazenamento (Figura 1). Maior incidência desta doença foi observada na cv. Tommy Atkins $(68,0 \%)$, diferindo significativamente das cvs. Palmer (12,0\%) e Keitt (18,0\%). A cv. Haden, com 36,0\% de incidência, diferiu estatisticamente da cv. Palmer. O tratamento com carbendazim reduziu a incidência da podridão peduncular nos frutos das cvs. Haden e Tommy Atkins, ao final do armazenamento.

A aplicação de ethefon na pré-colheita de manga cv. Haden, associado ao tratamento com carbendazim, levou a menor incidência da antracnose no início do armazenamento. Entretanto, tal controle deixou de ser significativo a partir do quarto dia de armazenamento (Figura 1A). Frutos tratados com ethefon apresentaram resultado similar ao tratamento com carbendazim, isto é, menor incidência da podridão peduncular quando comparados aos frutos não tratados, ao final do período de armazenamento.

A severidade da antracnose nas cultivares de manga foi baixa, no início do armazenamento $(<1 \%)$, mas aumentou de modo significativo nos frutos não tratados, durante o armazenamento (Figura 2). A cv. Keitt, seguida pela Haden, apresentou a maior severidade média, 11,2 e 6,6\%, respectivamente, diferindo das cvs. Palmer (1,3\%) e Tommy Atkins $(1,4 \%)$. O tratamento com carbendazim, embora não tenha reduzido a incidência de antracnose nos frutos, reduziu a severidade da doença nas cvs. Haden e Keitt. 


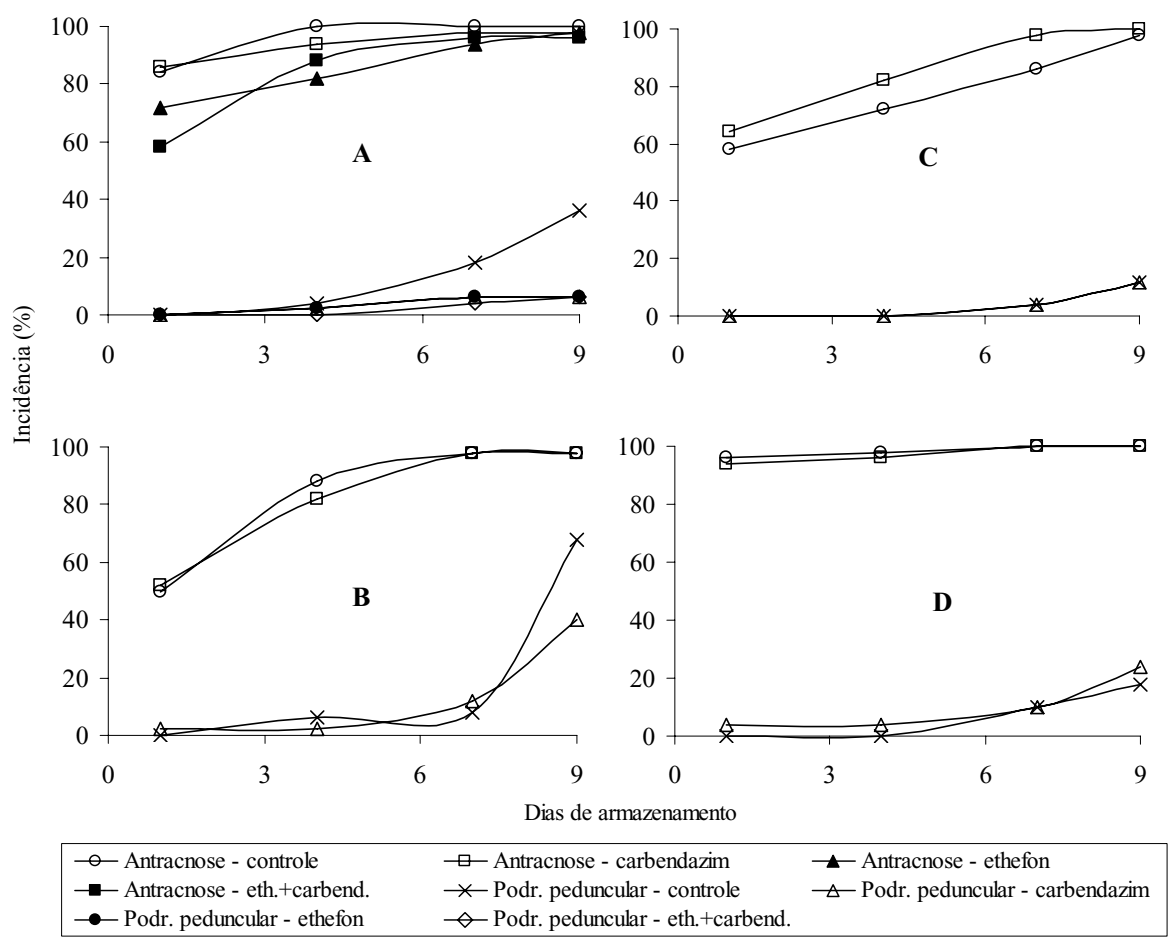

Figura 1. Incidência de antracnose e podridão peduncular de Lasiodiplodia em mangas cvs. Haden (A), Tommy Atkins (B), Palmer (C) e Keitt (D) submetidas ou não ao tratamento com carbendazim e/ou ethefon, armazenadas durante nove dias.

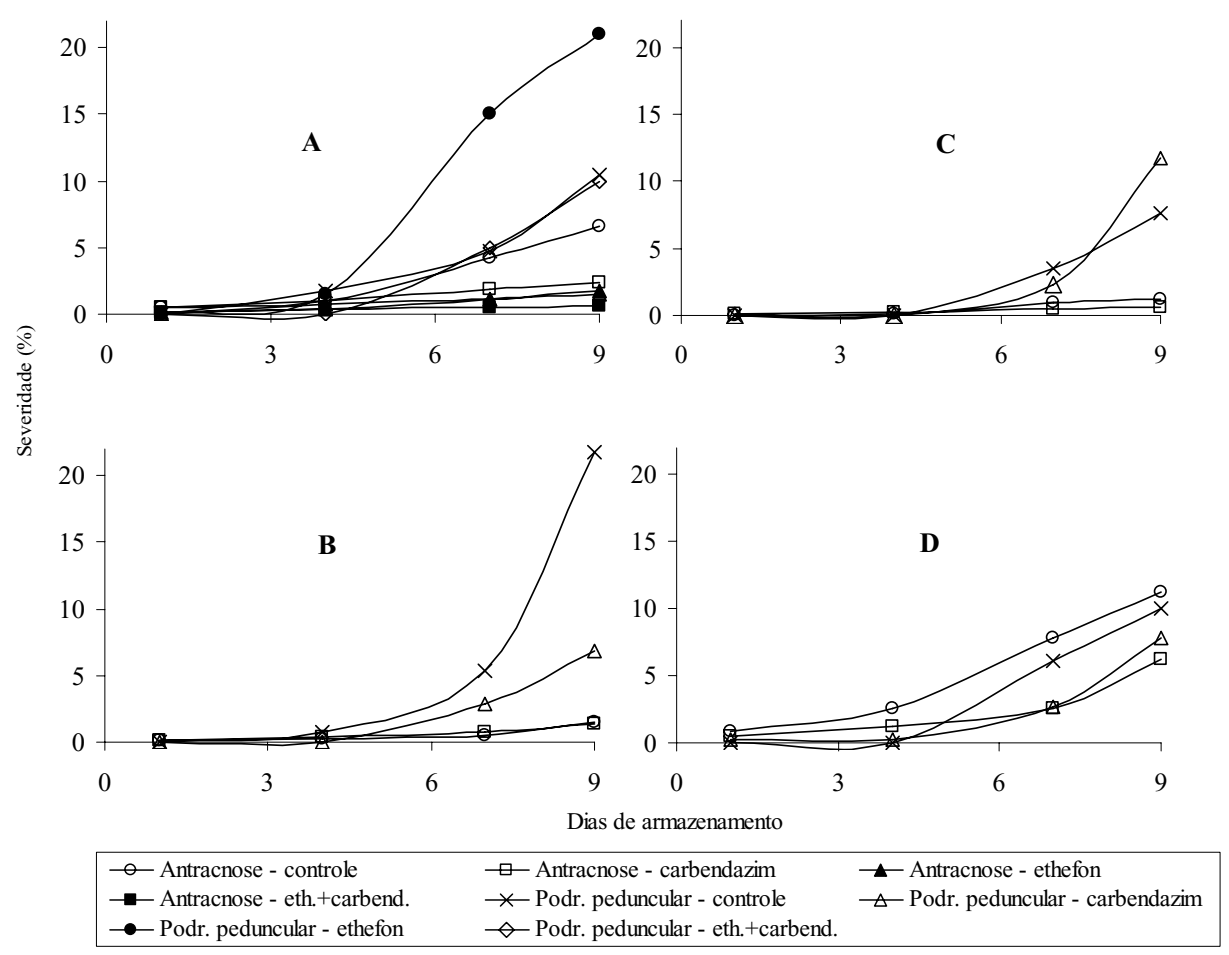

Figura 2. Severidade de antracnose e podridão peduncular de Lasiodiplodia em mangas cvs. Haden (A), Tommy Atkins (B), Palmer (C) e Keitt (D) submetidas ou não ao tratamento com carbendazim e/ou ethefon, armazenadas durante nove dias. 
A severidade da podridão peduncular aumentou significativamente durante o armazenamento dos frutos (Figura 2). Maior severidade nos frutos não tratados foi observada na cv. Tommy Atkins $(21,7 \%)$, seguida pelas cvs. Haden (10,5\%), Keitt (10,0\%) e Palmer (7,6\%). O tratamento com carbendazim reduziu, em 85,7 e $68,2 \%$, a severidade da podridão peduncular nas cvs. Haden e Tommy Atkins, respectivamente. A suscetibilidade da manga às podridões aumenta na pós-colheita durante $o$ armazenamento, devido a mudanças fisiológicas nos frutos, que favorecem o desenvolvimento dos patógenos (ECKERT at al., 1996).

A aplicação de ethefon e de carbendazim reduziu a severidade da antracnose na cv. Haden, o mesmo não ocorreu para a severidade da podridão peduncular, quando aplicado ethefon, o qual comprometeu até a eficiência do tratamento com carbendazim (Figura 2A). Prusky (1998) verificou que em frutos tratados com ethefon não ocorreu o desenvolvimento da antracnose até a maturação, indicando que, embora o etileno induza a formação de apressório de C. gloeosporioides no fruto, outras mudanças são necessárias na região da casca para que o apressório do fungo se desenvolva e cause a doença. Para a podridão peduncular, segundo Ploetz (2003), o tratamento com ethefon, antes do armazenamento dos frutos, pode favorecer o desenvolvimento da doença.

Os frutos das cultivares de manga avaliadas foram suscetíveis à antracnose e à podridão peduncular. As cvs. Tommy Atkins e Palmer apresentaram menor incidência da antracnose apenas no início do armazenamento. Segundo Manica et al. (2001) e Zambolim e Junqueira (2004), a cv. Tommy Atkins tem se mostrado menos suscetível à antracnose, quando comparada às cvs. Haden e Palmer. Mecanismos de resistência dos frutos de manga a patógenos podem estar relacionados a uma mistura de compostos antifúngicos presentes na casca (KOBILER et al., 1998). O composto antifúngico resorcinol, presente na casca do fruto de manga, tende a decrescer mais rapidamente durante a maturação nas cultivares suscetíveis, como a Haden, quando comparada às cultivares mais resistentes, como a Tommy Atkins (DROBY et al., 1986; PRUSKY; KEEN, 1993). Resistência média à antracnose é atribuída à cv. Keitt (MANICA et al., 2001). Entretanto, no presente estudo, foi a que apresentou a maior incidência e severidade da antracnose, provavelmente por ser a cultivar mais tardia, estando sujeita a maior potencial de inóculo do patógeno, com conseqüentemente mais infecções latentes. De acordo com Dodd et al. (1997), embora algumas cultivares apresentem resistência moderada, nenhuma é suficientemente resistente para ser produzida em áreas úmidas sem o uso de fungicidas.

A ocorrência de elevada temperatura e, principalmente, elevada umidade entre a floração e o desenvolvimento dos frutos, como ocorre na região Sudeste, favorecem as doenças como à antracnose e à podridão peduncular (MANICA et al., 2001; ZAMBOLIM; JUNQUEIRA, 2004). Apesar de amplamente disseminada em todas as regiões produtoras de manga no Brasil, a antracnose não causa danos expressivos nas regiões de clima seco segundo Cunha et al. (2000), o que tem motivado o plantio de pomares em regiões como as do semiárido nordestino. Já o aumento da incidência da podridão peduncular em várias localidades, como as áreas irrigadas da região Nordeste, é motivo de grande preocupação (CUNHA et al., 2000).

Os resultados obtidos confirmam a importância econômica das doenças pós-colheita em manga, visto que a simples presença dos sintomas desqualifica o fruto para comercialização, como destacado por Silva, Fonseca e Moreira (2007), que estimam perdas de até $30 \%$. Os elevados índices de podridões constatados neste estudo sugerem a necessidade do emprego de medidas de controle mais efetivas, durante a produção e pós-colheita da manga, buscando reduzir as perdas. Segundo Cunha et al. (1993), o tratamento térmico pela imersão dos frutos em água quente $\left(54 \pm 1^{\circ} \mathrm{C}\right)$ combinada com fungicida é mais eficiente que o fungicida isoladamente. 
Características fisicas e químicas

Os frutos apresentaram teores médios de sólidos solúveis na colheita de $13,9^{\circ}$ Brix para a cv. Haden, $15,6^{\circ}$ Brix para a cv. Tommy Atkins, $12,4^{\circ}$ Brix para a cv. Palmer e $14,6^{\circ}$ Brix para a cv. Keitt. (Tabela 1 ).
Verifica-se que os teores estavam acima de $10^{\circ}$ Brix, indicando que o ponto de maturação fisiológica e, conseqüentemente, o ponto de colheita já haviam sido atingidos (ASSIS, 2007).

Tabela 1. Teores de sólidos solúveis, acidez titulável e "ratio" de mangas cvs. Haden, Tommy Atkins, Palmer e Keitt avaliados no momento da colheita e após 9 dias de armazenamento a $25 \pm 2^{\circ} \mathrm{C}, 70-80 \% \mathrm{UR}$.

\begin{tabular}{ccccccc}
\hline \multirow{2}{*}{ Cultivares/Tratamentos } & \multicolumn{2}{c}{ Sólidos solúveis } & \multicolumn{2}{c}{ Acidez titulável } & \multicolumn{2}{c}{ "Ratio" } \\
\cline { 2 - 6 } & colheita & $9^{\circ}$ dia & colheita & $9^{\circ}$ dia & colheita & $9^{\circ}$ dia \\
\hline Haden 1 & $15,13 \mathrm{Aa}^{2}$ & $14,88 \mathrm{Aa}$ & $0,47 \mathrm{Aa}$ & $0,10 \mathrm{Ba}$ & $32,19 \mathrm{Aa}$ & $148,80 \mathrm{Ba}$ \\
Haden 2 & $15,13 \mathrm{Aa}$ & $15,00 \mathrm{Aa}$ & $0,47 \mathrm{Aa}$ & $0,08 \mathrm{Ba}$ & $32,19 \mathrm{Aa}$ & $187,50 \mathrm{Ba}$ \\
Haden 3 & $12,75 \mathrm{Ab}$ & $15,63 \mathrm{Ba}$ & $0,53 \mathrm{Aa}$ & $0,10 \mathrm{Ba}$ & $24,06 \mathrm{Aa}$ & $156,30 \mathrm{Ba}$ \\
Haden 4 & $12,75 \mathrm{Ab}$ & $15,75 \mathrm{Ba}$ & $0,53 \mathrm{Aa}$ & $0,10 \mathrm{Ba}$ & $24,06 \mathrm{Aa}$ & $157,50 \mathrm{Ba}$ \\
Tommy Atkins 1 & $15,63 \mathrm{Aa}$ & $16,00 \mathrm{Aa}$ & $0,31 \mathrm{Aa}$ & $0,10 \mathrm{Ba}$ & $22,01 \mathrm{Aa}$ & $160,00 \mathrm{Ba}$ \\
Tommy Atkins 2 & $15,63 \mathrm{Aa}$ & $16,63 \mathrm{Aa}$ & $0,31 \mathrm{Aa}$ & $0,10 \mathrm{Ba}$ & $50,42 \mathrm{Aa}$ & $166,30 \mathrm{Ba}$ \\
\hline Palmer 1 & $12,38 \mathrm{Aa}$ & $16,88 \mathrm{Ba}$ & $0,41 \mathrm{Aa}$ & $0,08 \mathrm{Ba}$ & $30,20 \mathrm{Aa}$ & $211,00 \mathrm{Ba}$ \\
Palmer 2 & $12,38 \mathrm{Aa}$ & $13,88 \mathrm{Ba}$ & $0,41 \mathrm{Aa}$ & $0,26 \mathrm{Ba}$ & $30,20 \mathrm{Aa}$ & $53,38 \mathrm{Ab}$ \\
Keitt 1 & $14,63 \mathrm{Aa}$ & $18,25 \mathrm{Ba}$ & $0,61 \mathrm{Aa}$ & $0,80 \mathrm{Aa}$ & $23,98 \mathrm{Aa}$ & $22,81 \mathrm{Aa}$ \\
Keitt 2 & $14,63 \mathrm{Aa}$ & $16,88 \mathrm{Ba}$ & $0,61 \mathrm{Aa}$ & $0,70 \mathrm{Aa}$ & $23,98 \mathrm{Aa}$ & $24,11 \mathrm{Aa}$ \\
\hline
\end{tabular}

${ }^{1} 1$ - sem ethefon, sem carbendazim; 2 - sem ethefon, com carbendazin, 3 - com ethefon, sem carbendazim, 4 - com ethefon, com carbendazim

${ }^{2}$ Médias seguidas de mesma letra, minúscula na coluna e maiúscula na linha, não diferem entre si para cada característica química analisada, ao nível de 5\% de significância.

Os sólidos solúveis são compostos por vitaminas, ácidos, açúcares, entre outros, sendo mais de $90 \%$ de sua composição representada pelos açúcares, portanto, é uma medida indireta do teor de açúcares (CHITARRA; CHITARRA, 2005).

Sabe-se que com a maturação dos frutos ocorre elevação nos teores de sólidos solúveis (CHITARRA; CHITARRA, 2005). Porém, verifica-se por meio dos resultados apresentados na Tabela 1, que não houve aumento dos teores de sólidos solúveis para as cvs. Tommy Atkins e Haden não tratadas com etephon durante o armazenamento, provavelmente devido ao estádio de maturação avançado na colheita.

Para todas as cultivares não foi observado efeito da aplicação do fungicida carbendazin nos teores de sólidos solúveis dos frutos (Tabela 1). Nos frutos da cv. Haden tratados com etephon foram observados os menores teores de sólidos solúveis no momento da colheita. No entanto, noves dias após a colheita, os teores de sólidos solúveis desses frutos assemelharam-se aos dos frutos não tratados com etephon, ou seja, a aplicação de ethefon não interferiu no acúmulo de açúcares dos frutos.

A acidez titulável das mangas estudadas apresentou redução durante o armazenamento, exceto a cv. Keitt. A acidez titulável das cvs. Haden, Tommy Atkins e Palmer decresceu de 0,43 g de ácido cítrico/100g de polpa, no dia da colheita, para 0,12 g de ácido cítrico/100g de polpa, no final do período de armazenamento. A redução dos teores de acidez também foi verificada por Jeronimo e Kanesiro (2000) em mangas Palmer, e por Jeronimo et al. (2007b) em cultivar de manga Tommy Atkins. O tratamento com fungicida e com etephon não influenciou na acidez dos frutos. 
O sabor dos frutos é função da relação sólidos solúveis:acidez titulável ("ratio") (CHITARRA; CHITARRA, 2005). Não houve efeito de tratamento nos valores de "ratio", exceto para os frutos da cultivar Palmer, que, quando tratados com fungicida, apresentaram menor "ratio" $(\mathrm{P}<0.05)$. Ao longo de nove dias houve aumento nos valores de "ratio", exceto para as mangas Palmer tratadas com fungicida e para frutos da cv. Keitt.

O tratamento com o fungicida carbendazim, embora tenha controlado a podridão peduncular das mangas cvs. Haden e Palmer e reduzido a severidade da antracnose das cvs. Haden e Keitt, não alterou a pressão de turgescência e nem a perda de massa dos frutos das diferentes cultivares. Estas variáveis foram afetadas apenas pelo tempo de armazenamento (Tabela 2). A maior perda de massa ao final de nove dias de armazenamento (aproximadamente 9\%) foi observada nas cvs. Haden e Keitt. Fonseca (1999) observou que após nove dias de armazenamento a temperatura ambiente $\left(19-34^{\circ} \mathrm{C}\right)$ e umidade relativa entre $46-97 \%$ houve $5 \%$ de perda de massa nos frutos de manga Haden, o que seria um valor aceitável pelo consumidor, uma vez que frutos com esse percentual de perda, ainda apresentam-se firmes e atrativos. No presente estudo, os frutos avaliados apresentaram média de perda de massa superior à massa admitida, caracterizados pelo fato de que dentre os frutos que foram submetidos à análise de perda de massa, em média 50\% encontravam-se impróprios para o consumo no final do armazenamento.

Tabela 2. Características físicas de cultivares de manga na colheita e após 9 dias de armazenamento a $25 \pm 2^{\circ} \mathrm{C}, 70$ $80 \%$ UR.

\begin{tabular}{ccccccrrr}
\hline Cultivares/ & \multicolumn{3}{c}{ Pressão de turgescência $\left({\left.\mathrm{Kg} . \mathrm{cm}^{-2}\right)}^{-}\right.$} & \multicolumn{3}{c}{ Perda de massa (\%) } \\
\cline { 2 - 9 } Tratamentos & colheita & $4^{\circ}$ dia & $7^{\circ}$ dia & $9^{\circ}$ dia & colheita & $4^{\circ}$ dia & $7^{\circ}$ dia & $9^{\circ}$ dia \\
\hline Haden & $0,64 \mathrm{~A}^{1}$ & $0,38 \mathrm{~B}$ & $0,32 \mathrm{BC}$ & $0,29 \mathrm{C}$ & - & $3,52 \mathrm{~B}$ & $7,40 \mathrm{~A}$ & $9,20 \mathrm{~A}$ \\
Tommy Atkins & $1,18 \mathrm{~A}$ & $0,34 \mathrm{~B}$ & $0,28 \mathrm{~B}$ & $0,26 \mathrm{~B}$ & - & $2,80 \mathrm{C}$ & $5,24 \mathrm{~B}$ & $7,45 \mathrm{~A}$ \\
Palmer & $0,51 \mathrm{~A}$ & $0,37 \mathrm{~B}$ & $0,36 \mathrm{~B}$ & $0,33 \mathrm{~B}$ & - & $1,39 \mathrm{C}$ & $4,85 \mathrm{~B}$ & $5,91 \mathrm{~A}$ \\
Keitt & $0,80 \mathrm{~A}$ & $0,51 \mathrm{~B}$ & $0,37 \mathrm{~B}$ & $0,35 \mathrm{~B}$ & - & $3,07 \mathrm{C}$ & $6,06 \mathrm{~B}$ & $9,36 \mathrm{~A}$ \\
\hline
\end{tabular}

${ }^{1}$ Médias seguidas de mesma letra na linha não diferem entre si ao nível de 5\% de significância.

\section{Conclusões}

A ocorrência de doenças em pós-colheita foi elevada nas cultivares de manga Haden, Tommy Atkins, Palmer e Keitt. Aantracnose foi a doença mais freqüente, com praticamente $100 \%$ de incidência nos frutos, seguida pela podridão peduncular com maior incidência nas cvs. Tommy Atkins e Haden.

O fungicida carbendazim apresentou eficiência variável no controle pós-colheita das podridões, em função da cultivar de manga, podendo ser recomendado para o controle da podridão peduncular, nas cvs. Haden e Palmer, e para reduzir a severidade da antracnose nas cvs. Haden e Keitt.

A aplicação de carbendazim não influenciou nos teores de sólidos solúveis, acidez titulável e "ratio" das cultivares de manga, exceto na cv. Palmer, que apresentou menor "ratio" quando tratada com o fungicida. A aplicação de ethefon em manga Haden possibilitou a fruta ser colhida mais verde, resistindo melhor aos impactos mecânicos durante o transporte. 


\section{Referências}

ALVES FILHO, J. P. Uso de agrotóxicos no Brasil: controle social e interesses corporativos. São Paulo: Annablume, 2002.

ARAUZ, L. F.; UMANA, G. Diagnostico e incidência de las enfermidades poscosecha del mango em Costa Rica. Agronomia Costarricense, San José, v.10, p.89-999, 1986.

ASSIS, J. S. Cultivo da mangueira: colheita e pós-colheita. Disponível em: <http://sistemasdeproducao.cnptia. embrapa.br/FontesHTML/Manga/CultivodaMangueira/ colheita.htm>. Acesso em: 21 out. 2007.

BARITELLE, J. L.; GARDNER, P. D. Economic losses in the food and fiber system: from the perspective of an economist. In: MOLINE, H. E. Postharvest pathology of fruits and vegetables: postharvest losses in perishable crops. California: University of California Agricultural Experiment Station Bulletin, 1984. p.4-10.

CALBO, A. G.; NERY, A. A. Medida de firmeza de hortaliças pela técnica de aplanação. Horticultura Brasileira, Campinas, v. 13, n. 1, p. 14-18, 1995.

CHITARRA, M. I. F.; CHITARRA, A. B. Pós-colheita de frutos e hortaliças: fisiologia e manuseio. 2.ed. Lavras: UFLA, 2005.

CHOUDHURY, M. Doenças pós-colheita da manga produzida na região do submédio São Francisco durante o período chuvoso. Revista Brasileira de Fruticultura, Cruz das Almas, v. 13, p. 289-291, 1991.

CUNHA, M. M., SANTOS FILHO, H. P.; NASCIMENTO, A. S. Manga. fitossanidade. Brasilia: EMBRAPA Mandioca e Fruticultura, 2000.

CUNHA, M. M.; COUTINHO, C. C.; JUNQUEIRA, N. T. V.; FERREIRA, F. R. Manga para exportação: aspectos fitossanitários. Brasília: Embrapa-SPI, 1993. (Série Publicações Técnicas FRUPEX).

DODD, J. C.; PRUSKY, D.; JEFFRIES, P. Fruit diseases. In: LITZ, R. E. The mango: botany, production and uses. Oxon, NY: CAB International, 1997. p.257-291.

DROBY, S.; PRUSKY, D.; JACOBY, B. Y.; GOLDMAN, A. Presence of an antifungal compounds and its relation in the latency of Alternaria alternata in unripe peel of mango fruits. Physiological and Molecular Plant Pathology, London, v. 25, p. 173-183, 1986.

ECKERT, J. W.; TARNAYAKE, M.; SIEVERT, J. R.; STRANGE, R. R. Curring citrus fruits to control postharvest diseases. In: CONGRESS OF THE INTERNATIONAL SOCIETY OF CITRICULTURE, 7., 1996, Sun City South Africa. Proceedings... Sun City South Africa:. Editora, 1996. v.48, p.
FONSECA, M. J. O. Efeito de fungicidas e cera na conservação pós-colheita de manga (Mangifera indica L.) 'Haden'. 1999. Tese (Doutorado em Fitotecnia) Universidade Federal de Viçosa, Viçosa.

FREITAS-SILVA, O.; ROCHA, E. S.; CÔRTES, M. V. C. B.; FREIRE JÚNIOR., M.; BITTENCOURT, A. A.; PIRES, L. F. G.; VITAL, H. C. Radiação gama no controle in vivo de Colletotrichum gloesporioides Penz. e Botryodiplodia theobromae em frutos de manga cv. Tommy Atkins. In: CONGRESSO BRASILEIRO DE FRUTICULTURA, 17., 2002, Belém, PA. Anais... Belém, PA: MP Design Gráfico, 2002. CDROM.

JERONIMO, E. M.; BRUNINI, M. A.; ARRUDA, M. C.; CRUZ, J. C. S.; FISCHER, I. H.; GAVA, G. J. C. Conservação pós-colheita de mangas 'Tommy Atkins' armazenadas sob atmosfera modificada. Semina: Ciência Agrárias, Londrina, v. 28, n. 3, p. 417-426, 2007 a.

JERONIMO, E. M.; BRUNINI, M. A.; ARRUDA, M. C.; CRUZ, J. C. S.; GAVA, G. J. C.; SILVA, M. A. Qualidade de mangas 'Tommmy Atkins' armazenadas sob atmosfera modificada. Ciência e Agrotecnologia, Lavras, v. 31, n. 4, p. 1122-1130, 2007b.

JERONIMO, E. M.; KANESIRO, M. A. B. Efeito da associação de armazenamento sob refrigeração e atmosfera modificada na qualidade de mangas 'Palmer'. Revista Brasileira de Fruticultura, Jaboticabal, v. 22, n. 2, p. 237-243, 2000.

JUNQUEIRA, N. T. V.; PINTO, A. C. Q.; CUNHA, M. M.; RAMOS, V. H. V. Controle das doenças da mangueira. In: ZAMBOLIM, M. L. Controle de doenças de plantas: fruteiras. Viçosa: UFV, 2002. v. 1, p. 323-404.

KOBILER, I.; REVED, R.; ARTEZ, L.; PRUSKY, D. Antifugal compounds regulating quiescent diseases in mango. ACIAR Proceedings Series, Canberra, v. 80, p. 109-114, 1998.

MANICA, I.; ICUMA, I. M.; MALAVOLTA, E.; RAMOS, V. H. V.; OLIVEIRA JÚNIOR, M. E. O.; CUNHA, M. M.; JUNQUEIRA, N. T. V. Tecnologia, produção, agroindústria e exportação de manga. Porto Alegre: Cinco Continentes, 2001.

MARANCA, G. Fruticultura comercial: manga e abacate. São Paulo: Nobel, 1980.

MORAES, W. S.; ZAMBOLIM, L.; LIMA, J. D. Incidência de fungos em pós-colheita de banana 'Prata anã' (Musa AAB). Summa Phytopathologica, Botucatu, v. 32, n. 1, p. 67-70, 2006.

PFAFFENBACH, L. B.; CASTRO, J. V.; CARVALHO, C. L., ROSSETO, C. J. Efeito da atmosfera modificada e da refrigeração na conservação pós-colheita de manga 
espada vermelha. Revista Brasileira de Fruticultura, Jaboticabal, v. 25, n. 3, p. 410-413. 2003.

PLOETZ, R. C. Diseases of mango. In: PLOETZ, R. C. Diseases of tropical fruit crops. Wallingford, CAB International, 2003. p. 327-363.

PRUSKY, D. Mecanisms of resistance of fruits and vegetables to postharvest diseases. ACIAR Proceedings Series, Canberra, v. 80, p. 19-33, 1998.

PRUSKY, D.; KEEN, N. T. Involvement of preformed antifungal compounds in the resistance of subtropical fruits to fungal decay. Plant Disease, Saint Paul, v. 77, p. 114-119, 1993.

RIBEIRO, I. J. A. Doenças da mangueira (Mangifera indica L.). In: KIMATI, H.; AMORIM, A.; BERGAMIN-
FILHO, A.; CAMARGO, L. E. A.; REZENDE, J. A. M. Manual de fitopatologia. São Paulo: Agronômica Ceres, 1997. v. 2, p. 511-524.

SILVA, C. R. R.; FONSECA, E. B. A.; MOREIRA, M. A. A cultura da mangueira. Disponível em: <http:// www.editora.ufla.br/Boletim/pdfextensao/bol_24.pdf.>. Acesso em: 21 mar.2007.

ZAMBOLIM, L.; JUNQUEIRA, N. T. V. Manejo integrado de doenças da mangueira. In: ROZANE, D. E.; DAREZZO, R. J.; AGUIAR, R. L.; AGUILERA, G. H. A.; ZAMBOLIM, L. Manga: produção integrada, industrialização e comercialização. Viçosa: Universidade Federal de Viçosa, 2004. v. 1, p. 377-408.

ZAR, J. H. More on dichotomus variables. In: ZAR, J. H. Biostatistical analyis. New Jersey: Prentice-Hall, 1999. p. 516-570. 